\title{
Crescimento alométrico de componentes da carcaça de bezerros de origem leiteira na fase inicial do crescimento pós-natal
}

\author{
Alometric growth of carcass components of new born male dairy calves
}

\author{
Paulo Afonso Carvalho ${ }^{\mathrm{I}}$ Luis Maria Bonnnecarrère Sanchez ${ }^{\mathrm{II}}$ \\ João Pedro Velho ${ }^{\text {III }}$ Cleber Cassol Pires ${ }^{\text {II }}$ Julio Viegas $^{\text {II }}$
}

\section{RESUMO}

Foi avaliado o crescimento diferencial de componentes da carcaça de bezerros de origem leiteira, na fase inicial da vida produtiva. Foram abatidos 18 bezerros da raça Holandesa, sendo seis ao nascimento, seis aos 50 e seis aos 110 dias de idade. Foi avaliada a composição da carcaça, em função do peso da carcaça fria. $O$ estudo do crescimento alométrico foi realizado utilizando-se a equação $Y=a X^{b}$, transformada logaritmamente em regressão linear. Houve acréscimo $(P<0,01)$ no peso de carcaça fria, osso, músculo, gordura, dianteiro, costilhar e traseiro, do nascimento aos 110 dias de vida. O percentual de dianteiro diminuiu linearmente $(P<0,01)$, enquanto que os percentuais de gordura e de traseiro aumentaram linearmente $(P<0,01)$ com o aumento do peso de carcaça fria. Houve crescimento isogônico $(b=1)$ dos tecidos ósseo e muscular, demonstrando que, até os 110 dias de vida, estes tecidos cresceram em igual intensidade que a carcaça, enquanto que o tecido adiposo apresentou crescimento tardio $(b>1)$. Foi observado crescimento precoce $(b<1)$ para o dianteiro, cerscimento isogônico $(b=1)$ para o costilhar $e$ crescimento tardio $(b>1)$ para o traseiro. Os componentes da carcaça apresentaram distintos padrões de crescimento, merecendo especial atenção no estabelecimento de um sistema de produção de carcaças oriundas de bezerros de origem leiteira.

Palavras-chave: alometria, gordura, músculo, osso.

\section{ABSTRACT}

This study was aimed at evaluating the differential growth of carcass components of new born dairy calves. Eighteen Friesian calves were slaughtered, at birth or at 50 or 110 days of age; six at each age. The alometric growth of carcass components in relation to cold carcass weight was studied by the use of the equation $Y=a X^{b}$ adjusting linear regressions to the log of the data. From birth to 110 days of age the weight of cold carcass, bone, muscle and fat, forequarter, $r i b$ and hindquarter increased $(P<0.01)$. As proportion of the cold carcass weight, the weight of forequarter decreased linearly $(P<0.01)$ but those of hindquarter and fat increased $(P<0.01)$. The growth pattern up to 110 days of age for tissues was isogonic with the carcass for bone and muscle $(b=1)$, and late $(b>1)$ for fat; about carcass components, growth was early for forequarter $(b<1)$, isogonic for rib $(b=1)$ and late for hindquarter $(b>1)$. It was concluded that the characteristic growth pattern of carcass components should be considered at developing a system of calves' carcasses production.

Key words: alometric, bone, fat, muscle.

\section{INTRODUÇÃO}

Nos sistemas de produção de leite, o bezerro macho recebe um tratamento bastante inferior em relação à fêmea, devido a objetivos de produção e dificuldades na implantação de um sistema criatório eficiente para este tipo de animal.

Anualmente, nas principais bacias leiteiras do Brasil, milhares de bezerros machos são sacrificados ao nascer, eliminando-se assim uma fonte de renda em potencial. Os machos de raças mais apuradas são sacrificados logo após o nascimento, pois, apesar de sua capacidade para ganhar peso, não conseguem se adaptar às condições rústicas de um sistema de criação mais extensivo (RIBEIRO et al., 2001).

\footnotetext{
IPrograma de Pós-graduação, Departamento de Zootecnia, Universidade Federal de Santa Maria (UFSM). Rua Lamartine Babo, 750, Camobi, Santa Maria, RS, Brasil. 97105.230. E-mail: pac@mail.ufsm.br. Autor para correspondência.

"Departamento de Zootecnia, UFSM, Santa Maria, RS, Brasil.

IIIPrograma de Pós-graduação em Zootecnia, UFRGS, Porto Alegre, RS, Brasil.
} 
A determinação dos fatores relacionados ao crescimento de bezerros machos de origem leiteira é desejável, com o intuito de avaliar-se uma possível viabilização e o retorno econômico para esta categoria animal, que é, atualmente, sub-aproveitada. Todavia, o desempenho produtivo dos bezerros pode ser comprometido por restrições alimentares impostas a estes animais (ROCHA et al., 1999). Os conhecimentos da influência do genótipo, da nutrição e do estágio de maturação sobre o crescimento dos bezerros assumem grande importância, pois a composição corporal repercute sobre as necessidades nutricionais e o desempenho produtivo do animal.

O crescimento compreende transformações no tamanho e na estrutura do corpo, que acontecem no decorrer da vida produtiva (HAMMOND, 1966). Este processo envolve a construção de tecidos nos órgãos, ossos, músculos e na gordura e apresenta distintos ímpetos de crescimento entre as diferentes partes da carcaça e dos tecidos que a constituem, de acordo com a fase de crescimento e a maturidade fisiológica dos animais envolvidos (BERG \& BUTTERFIELD, 1976). Isso caracteriza que o crescimento destes tecidos não ocorre de forma isométrica, ou seja, cada um terá um impulso de crescimento em distintas fases da vida do animal (ENSMINGER et al. 1990).

Entretanto, a grande maioria dos estudos realizados nessa área envolve uma curva de crescimento bastante ampla, entendendo-se até a maturidade dos animais ou próximo desta. Existem poucas informações a respeito do crescimento diferencial ocorrido apenas na fase neonatal ou imediatamente após o nascimento. É justamente nesta fase de crescimento que o bezerro macho de origem leiteira é comumente submetido a restrições alimentares, o que destaca a relevância de tais informações.

Neste sentido, este trabalho objetivou avaliar o crescimento diferencial de componentes da carcaça de bezerros de origem leiteira, na fase inicial da vida produtiva.

\section{MATERIAL E MÉTODOS}

O experimento foi conduzido no Setor de Nutrição de Ruminantes, pertencente ao Departamento de Zootecnia da Universidade Federal de Santa Maria, RS. Foram abatidos 18 bezerros machos da raça Holandesa, não-castrados, sendo seis ao nascimento, seis aos 50 dias e seis aos 110 dias de idade. Logo após o nascimento, os bezerros foram separados das vacas e confinados em baias individuais até o dia preestabelecido para o sacrifício. Durante este período, receberam alimentação sólida à vontade e láctea controlada (consumo máximo de $4 \mathrm{~L}$ animal ${ }^{-1} \mathrm{dia}^{-1}$ de leite integral no balde). No início da segunda semana, foi introduzido um concentrado com $18 \%$ de PB. Também foram ofertados água e feno de alfafa (Medicago sativa) picado, a partir do início da segunda e da terceira semana, respectivamente. O desaleitamento ocorreu gradativamente dos 28 aos 50 dias de vida, diminuindo-se o fornecimento em $1 \mathrm{~L}$ leite animal ${ }^{-1}$ dia $^{-1} \mathrm{a}$ cada semana e excluindo-o da dieta, a partir dos 50 dias.

Ao atingir a idade de abate, os animais foram pesados e sacrificados por secção da carótida e da jugular. Por ocasião do abate, foram retirados pele, vísceras, cabeça e pés/canela, obtendo-se a carcaça quente. Após o resfriamento por 24 horas e pesagem das carcaças frias, realizou-se a divisão da meia carcaça esquerda em dianteiro (por corte transversal entre a 8-9avértebra torácica), costilhar (por corte longitudinal rente ao músculo longissimus dorsi) e traseiro (por corte transversal entre a $11^{\mathrm{a}}$ e $12^{\mathrm{a}}$ vértebra torácica, ficando com as duas últimas costelas). As composições de osso, músculo e gordura da carcaça foram determinadas por dissecação total dos tecidos nas diferentes regiões, extrapolando-se para a carcaça inteira.

O delineamento experimental foi inteiramente casualisado, constando de três tratamentos (idades de abate) e seis repetições por tratamento, sendo a unidade experimental representada por um animal. Os dados foram submetidos à análise de regressão, considerando-se como variável independente o peso de carcaça fria.

O estudo da determinação do crescimento alométrico das diferentes regiões e de osso, músculo e gordura em relação à carcaça foi realizado através da equação preconizada por HUXLEY (1932), definida pelo modelo $\mathrm{Y}=\mathrm{aX} \mathrm{X}^{\mathrm{b}} . \varepsilon$, logaritmizada na forma $\ln \mathrm{Y}=\ln \mathrm{a}+\mathrm{b}$ $\ln \mathrm{X}+\varepsilon$, em que $\mathrm{Y}$ é a variável resposta (peso de cada região ou tecido), a é o intercepto, b é o coeficiente de alometria, X é a variável explicativa (peso de carcaça fria) e $\varepsilon$ é o erro aleatório incorporado ao modelo. Para testar a hipótese $\mathrm{b} \neq 1$, usou-se o teste " $\mathrm{t}$ " de Student aos níveis de 5 e $1 \%$ de significância. O crescimento foi considerado isogônico quando tem-se $b=1$, significando que o crescimento da região da carcaça ou do tecido em questão foi igual ao crescimento da carcaça. Quando $b \neq 1$, o crescimento da região ou do tecido foi heterogônico precoce $(b<1)$ ou tardio $(b>1)$, em relação à carcaça fria. As análises estatísticas foram realizadas através do programa SAS (1996).

\section{RESULTADOS E DISCUSSÃO}

Na tabela 1, estão apresentadas as médias obtidas para os pesos e rendimentos de carcaça fria, 
Tabela 1 - Valores médios, coeficientes de determinação $\left(\mathrm{R}^{2}\right)$ e equações de regressão ajustadas para peso e rendimento de carcaça fria, peso e rendimento de tecidos da carcaça e peso e rendimento de regiões da carcaça, em função do peso de carcaça fria de bezerros de origem leiteira

\begin{tabular}{|c|c|c|c|c|c|}
\hline \multirow{2}{*}{ Característica } & \multicolumn{3}{|c|}{ Idade (dias) } & \multirow{2}{*}{$\mathrm{R}^{2}(\%)$} & \multirow{2}{*}{ Equação de regressão } \\
\hline & Nasc & 50 & 110 & & \\
\hline Carcaça fria (kg) & 21,79 & 30,07 & 40,69 & - & $\ddot{y}=1 \mathrm{PCF}$ \\
\hline Carcaça fria (\%) & 53,18 & 50,27 & 46,72 & 35,80 & $\ddot{y}=56,755991-0,217178 * *$ PCF \\
\hline Osso (kg) & 6,60 & 8,57 & 10,32 & 84,15 & $\ddot{\mathrm{y}}=2,023281+0,209771^{* *}$ PCF \\
\hline Osso (\%) & 29,75 & 28,61 & 25,47 & - & $\ddot{y}=27,94$ \\
\hline Músculo (kg) & 14,07 & 19,77 & 27,18 & 98,32 & $\ddot{y}=-0,768970+0,684303 * *$ PCF \\
\hline Músculo (\%) & 65,10 & 65,72 & 66,73 & - & $\ddot{y}=65,85$ \\
\hline Gordura (kg) & 1,06 & 1,66 & 2,96 & 80,50 & $\ddot{y}=-1,015332+0,094218 * *$ PCF \\
\hline Gordura (\%) & 4,89 & 5,43 & 7,28 & 39,30 & $\ddot{y}=2,574734+0,106752 * *$ PCF \\
\hline Dianteiro (kg) & 8,24 & 10,63 & 14,23 & 98,69 & $\ddot{y}=0,895475+0,328598 * *$ PCF \\
\hline Dianteiro (\%) & 37,93 & 35,37 & 34,89 & 39,92 & $\ddot{y}=39,819083-0,121785^{* *}$ PCF \\
\hline Costilhar (kg) & 3,21 & 4,23 & 5,68 & 94,92 & $\ddot{y}=0,417948+0,128253^{* *}$ PCF \\
\hline Costilhar (\%) & 14,81 & 14,07 & 14,00 & - & $\ddot{y}=14,29$ \\
\hline Traseiro (kg) & 10,33 & 15,21 & 20,70 & 99,57 & $\ddot{y}=-1,186041+0,538053 * *$ PCF \\
\hline Traseiro (\%) & 47,27 & 50,56 & 50,90 & 54,09 & $\ddot{y}=44,744375+0,156599 * *$ PCF \\
\hline
\end{tabular}

** $(\mathrm{P}<0,01)$; ns $(\mathrm{P}>0,05)$ pelo teste de Tukey; Nasc= nascimento; $\mathrm{PCF}=$ peso de carcaça fria.

de osso, de músculo, de gordura, de dianteiro, de costilhar e de traseiro, de acordo com diferentes idades de abate, assim como as equações de regressão ajustadas para essas variáveis, em função do peso de carcaça fria.

Houve acréscimo de 86,7\%, em média, no peso de carcaça fria do nascimento aos 110 dias de vida. Todavia, também foi verificada redução de $12,2 \%$, em média, no rendimento de carcaça fria, no mesmo período, o que pode ser explicado pelo aumento acentuado do trato gastrintestinal, principalmente do rúmen. Conforme SIGNORETTI et al. (1999), naturalmente ocorre redução no rendimento de carcaça de bezerros submetidos a dietas compostas por volumoso. Segundo estes autores, tal fato ocorre devido ao crescimento e enchimento do trato gastrintestinal até um certo limite de peso vivo, a partir do qual maiores ganhos são obtidos em função de reservas corporais.

As deposições absolutas de osso, músculo e gordura foram influenciadas $(\mathrm{P}<0,01)$ linearmente pelo peso de carcaça fria, ocasionando acréscimos quantitativos destes tecidos conforme o incremento de peso, o que já era esperado. Segundo HAMMOND (1966), crescimento é um processo que ocorre naturalmente, ocasionando aumento de peso e tamanho até que o animal alcance a maturidade. Já com relação à deposição relativa destes tecidos, verificaramse distintos padrões de crescimento.
Do nascimento aos 110 dias de vida, a proporção de ossos na carcaça diminuiu em 14,4\%, embora não linearmente ao acréscimo do peso da carcaça fria. A proporção de músculo da carcaça não foi alterada, enquanto que a proporção de gordura da carcaça apresentou acréscimo linear $(\mathrm{P}<0,01)$ de 48,9\% do nascimento até os 110 dias de vida. Tais resultados estão de acordo com relatos de BERG \& BUTTERFIELD (1976) e de WOOD et al. (1980), que afirmam que o crescimento relativo dos tecidos tem a seguinte ordem: osso, músculo e gordura. Da mesma forma, TAYLOR (1985) relatou ocorrer diminuição da proporção de ossos, pouca mudança na proporção de músculo e aumento da proporção de gordura na carcaça, conforme o desenvolvimento animal.

Houve acréscimos lineares $(\mathrm{P}<0,01)$ nos pesos absolutos de dianteiro, costilhar e traseiro, de acordo com o incremento do peso de carcaça fria (Tabela 1), o que também já era esperado. Com o aumento de peso total do animal, as partes que o compõem também devem aumentar, muito embora apresentem velocidades de crescimento diferenciado (DI MARCO, 1994). Foram observadas reduções no percentual de dianteiro e acréscimo no percentual de traseiro, enquanto que o percentual de costilhar manteve-se igual do nascimento até os 110 dias de vida.

As alterações observadas neste estudo, para os percentuais de tecidos e regiões da carcaça, demonstram distintos padrões de crescimento. Durante 
o crescimento, os diferentes componentes do corpo não crescem na mesma velocidade que a massa total do corpo. Este crescimento diferencial provoca mudanças nas características de forma, estrutura anatômica, composição do corpo e conseqüente desenvolvimento animal (BONNECARRÈRE SANCHEZ, 1976). Neste sentido, VERDE (1996) relatou que o crescimento pode ser mais bem avaliado por meio de equações exponenciais, nos quais cada unidade pode ser comparada ao crescimento total, identificando o crescimento diferencial das partes e dos tecidos, relacionando-o a mudanças na composição da carcaça. Na tabela 2, são apresentadas as equações alométricas de osso, músculo, gordura, dianteiro, costilhar e traseiro, em função do peso da carcaça fria. Os coeficientes de alometria indicam que houve crescimento isogônico $(b=1)$ dos tecidos ósseo e muscular, demonstrando que, até os 110 dias de vida, estes tecidos cresceram em igual intensidade que a carcaça, enquanto que o tecido adiposo apresentou crescimento tardio ( $\mathrm{b}>1)$.

O padrão de crescimento dos tecidos muscular e adiposo, observados neste estudo, era esperado, o que está de acordo com o comportamento descrito por BERG \& BUTTERFIELD (1976). Entretanto, o crescimento isogônico obtido para o tecido ósseo é um dado valioso, que demonstra claramente o elevado ímpeto de crescimento ósseo até os 110 dias de idade. Como relatado anteriormente, a maioria dos estudos realizados nesta área contempla uma curva de crescimento muito ampla, em que o tecido ósseo apresenta crescimento precoce em relação à carcaça. Ao realizar o fracionamento da curva, observa-se uma distinção nesse comportamento (Figura 1).

Existem poucas informações sobre crescimento neonatal de bezerros machos de origem

Tabela 2 - Equações do crescimento alométrico de osso, músculo, gordura, dianteiro, costilhar e traseiro em relação à carcaça fria; Teste t; padrão de crescimento (b) e coeficiente de determinação $\left(\mathrm{R}^{2}\right)$ das equações ajustadas para bezerros da raça Holandesa, do nascimento aos 110 dias de vida.

\begin{tabular}{lccc}
\hline Equação Log $\mathrm{Y}=\log \mathrm{a}+\mathrm{b} \log \mathrm{X}$ & Teste t & $\mathrm{b}$ & $\mathrm{R}^{2}(\%)$ \\
\hline Ln osso $=-0,8854+0,8825 \ln \mathrm{PCF}^{1}$ & $\mathrm{~ns}$ & $\mathrm{~b}=1$ & 81,58 \\
Ln músculo $=-0,4379+1,0056 \ln$ PCF & $\mathrm{ns}$ & $\mathrm{b}=1$ & 97,75 \\
Ln gordura $=-4,5031+1,4834 \ln$ PCF & $* *$ & $\mathrm{~b}>1$ & 83,27 \\
Ln dianteiro $=-0,6623+0,8941$ ln PCF & $* *$ & $\mathrm{~b}<1$ & 98,42 \\
Ln costilhar $=-1,6240+0,9045 \ln$ PCF & ns & $\mathrm{b}=1$ & 95,79 \\
Ln traseiro $=-1,0495+1,1025 \ln$ PCF & $* *$ & $\mathrm{~b}>1$ & 99,52 \\
\hline
\end{tabular}

**significativo a $1 \%$ de probabilidade; ns = não significativo pelo Teste $\mathrm{t} ; 1$ = peso de carcaça fria. leiteira. Todavia, é justamente nesta fase que este tipo de animal é descartado, destacando a relevância destas informações. O crescimento do tecido ósseo, do nascimento até os 110 dias de vida, implica incremento na retenção de macrominerais na composição do corpo vazio. Este é um aspecto a se considerar durante a fase de cria e início da recria de bezerros machos de origem leiteira. De acordo com BOIN (1995), a formulação de concentrados e suplementos para determinados níveis de desempenho, assim como a estimativa do desempenho a partir de dietas balanceadas, exige o conhecimento da composição corporal e conseqüentes exigências nutricionais para diferentes categorias animais, funções e níveis de desempenho.

A estimativa de composição tecidual em osso, músculo e gordura na carcaça (Figura 1), obtida através do modelo exponencial preconizado por HUXLEY (1932), contempla curvas que demonstram ocorrer, nesta fase de vida, uma elevada proporção de ossos e reduzida proporção de gordura na carcaça dos bezerros, mesmo aos 110 dias.

Os coeficientes alométricos (b) demonstram que o aumento do peso de carcaça implica aumento na velocidade de deposição de gordura $(b=1,4834)$, o que não ocorre com a deposição óssea $(b=0,8825)$. A deposição muscular ocorre em igual intensidade que o incremento de peso das carcaças $(b=1,0056)$. De acordo com BERG \& BUTTERFIELD (1976), ao nascimento, existem na carcaça cerca de duas partes de músculo para uma de osso; no entanto, o músculo cresce relativamente mais rápido no período pós-natal do que o osso, fazendo com que a relação de músculo para osso aumente. Já a gordura, que representa uma porção pequena ao nascimento, aumenta de maneira mais acentuada após a maturidade fisiológica, sendo o tecido mais variável do organismo animal e de mais fácil manipulação na carcaça.

Foi observado (Tabela 2) crescimento precoce $(b<1)$ para o dianteiro, isogônico $(b=1)$ para o costilhar e crescimento tardio $(\mathrm{b}>1)$ para o traseiro. $\mathrm{O}$ crescimento precoce do dianteiro, observado neste estudo, está de acordo com os modelos de desenvolvimento disto-proximal e antero-posterior propostos por HAMMOND (1932), em que quanto mais jovem o animal, maior será a proporção das extremidades e da região anterior, em relação a animais adultos. As distintas velocidades de crescimento das diferentes regiões dos animais ficam mais evidentes à medida que eles crescem, estabilizando-se com a maturidade.

A figura 2 apresenta as curvas exponenciais de composição regional da carcaça, estimadas pelo modelo de HUXLEY (1932). Verifica-se maior 


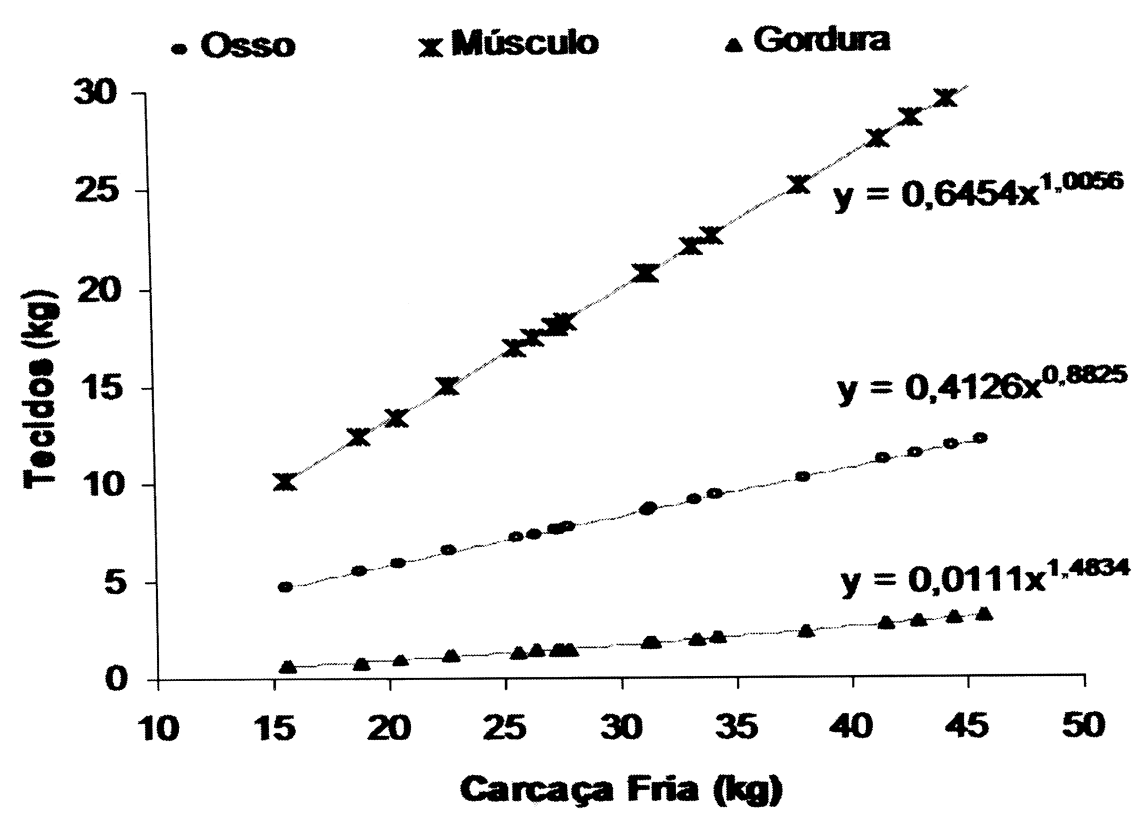

Figura 1 - Crescimento alométrico de osso, músculo e gordura em relação ao peso de carcaça fria de bezerros da raça Holandesa, do nascimento aos 110 dias de vida.

participação do traseiro, intermediária do dianteiro e menor do costilhar, na composição da carcaça, do nascimento aos 110 dias. Entretanto, estas partes apresentam distintas velocidades de crescimento, em relação ao crescimento total da carcaça.

Os coeficientes alométricos (b) demonstram que, aumentando o peso de carcaça, ocorre redução na velocidade de crescimento do dianteiro ( $b=0,8941)$. O ímpeto de crescimento do costilhar ( $b=0,9045)$ ocorre em mesma intensidade que o crescimento da carcaça, até os 110 dias de idade. O crescimento do traseiro ocorre em menor velocidade que o das carcaças ( $b=1,1025)$, obtendo-se maiores proporções de traseiro à medida que o animal se desenvolve, o que é desejável do ponto de vista produtivo.

Segundo ROCHA et al. (1999), no contexto da realidade brasileira, o aproveitamento racional para corte dos bezerros de origem leiteira exige melhor

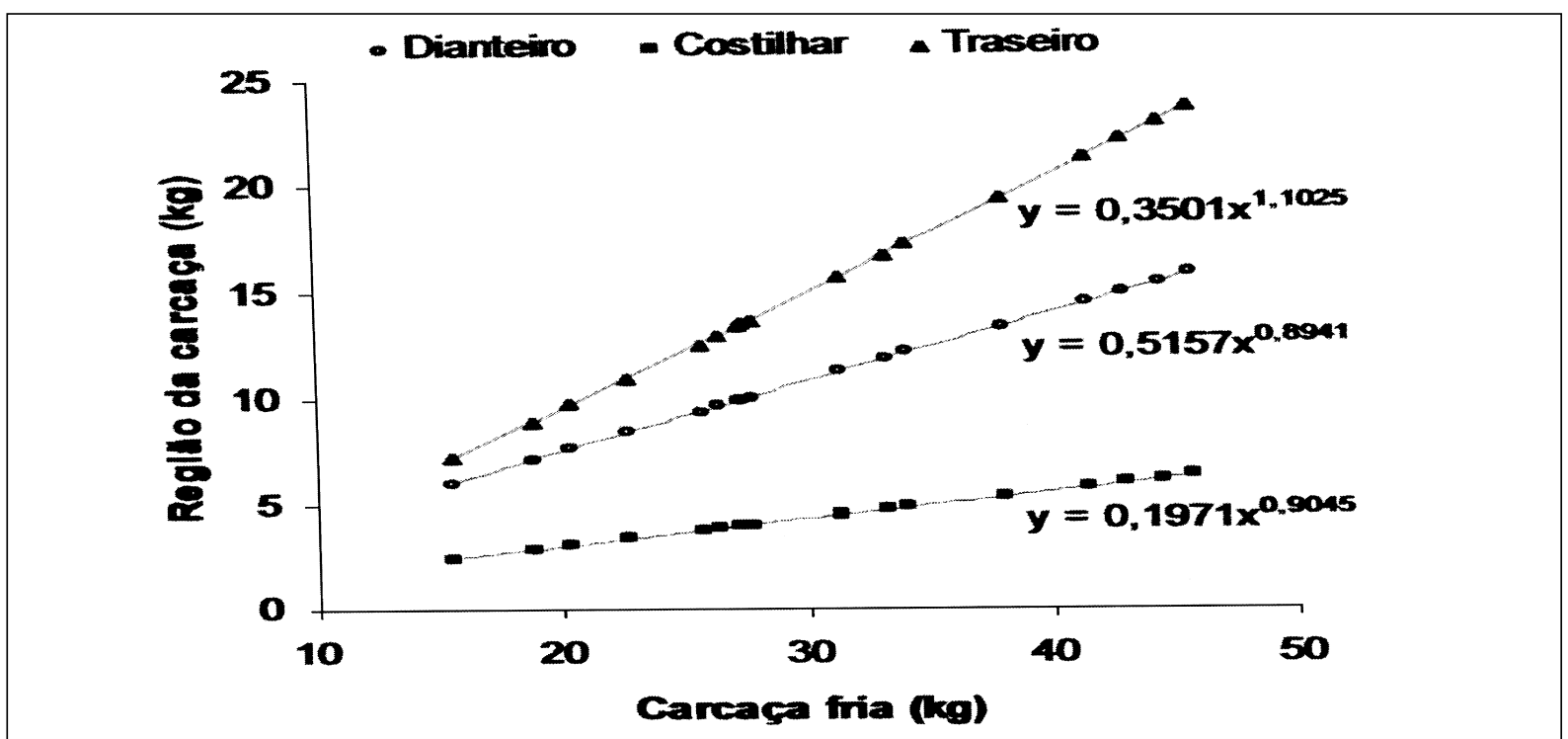

Figura 2 - Crescimento alométrico de dianteiro, costilhar e traseiro em relação ao peso de carcaça fria de bezerros da raça Holandesa, do nascimento aos 110 dias de vida.

Ciência Rural, v.37, n.1, jan-fev, 2007. 
avaliação do potencial de crescimento e das características das carcaças. Assim, devem ser considerados os diferentes padrões de crescimento dos componentes da carcaça.

\section{CONCLUSÕES}

Os componentes da carcaça apresentaram distintos padrões de crescimento, merecendo especial atenção no estabelecimento de um sistema de produção de carcaças oriundas de bezerros de origem leiteira. Todavia, recomenda-se a realização de mais estudos sobre o processo de crescimento diferencial da carcaça de animais de origem leiteira na busca de informações complementares.

\section{REFERÊNCIAS}

BERG, R.T.; BUTTERFIELD, R.M. New concepts of cattle growth. Sidney: Sidney University, 1976. 240p.

BOIN, C. Alguns dados sobre exigências de energia e de proteína de zebuínos. In: SIMPÓSIO INTERNACIONAL SOBRE EXIGÊNCIAS NUTRICIONAIS DE RUMINANTES, 1995, Viçosa, MG. Anais... Viçosa: Universidade Federal de Viçosa, 1995. p.457-465.

BONNECARRÈRE SANCHEZ, L.M. Food intake of sheep as affected by diet and body composition. 1976. 250f. Thesis (Doctor of Philosophy) - University of Aberdeen, Aberdeen.

DI MARCO, O.N. Crecimiento y respuesta animal. Balcarce: Asociación Argentina de Producción Animal (AAPA), 1994. 129p.

ENSMINGER, M.E. et al. Feeds and nutrition. 2.ed. Clovis: Califórnia, 1990. 1544p.
HAMMOND, J. Growth and development of mutton qualities in the sheep. Edinburgo: Oliver and Boyd, 1932. 595p.

HAMMOND, J. Principios de la explotación animal. Zaragoza: Acríbia, 1966. 363p.

HUXLEY, J.S. Problems of relative growth. London: Methuen, 1932. 577p.

RIBEIRO, T.R. et al. Influência do plano nutricional sobre o desempenho de bezerros holandeses para produção de vitelos Revista Brasileira de Zootecnia, v.30, n.6 (suplemento), p.2145-2153, 2001.

ROCHA, E. de O. et al. Ganho de peso, eficiência alimentar e características da carcaça de novilhos de origem leiteira. Revista da Sociedade Brasileira de Zootecnia, v.28, n.1, p.148158, 1999.

SIGNORETTI, R.D. et al. Crescimento, conversão alimentar e rendimento de carcaça de bezerros da raça holandesa alimentados com dietas contendo diferentes níveis de volumoso. Revista Brasileira de Zootecnia, v.28, n.1, p.185-194, 1999.

Statistical Analysis System. Software, Version 6.11. Cary, 1996. CD-Rom.

TAYLOR, C.S. Use of genetic size scaling in evaluation of animal growth. Journal Animal Science, Champaign, v.61, suppl.2, p.119-143, 1985.

VERDE, L.S. Crescimento e crescimento compensatório na produção animal. Santa Maria, RS: Universidade Federal de Santa Maria, 1996. 23p. (Curso Extra-Curricular).

WOOD, J.D. et al. Carcass composition in four sheep breeds: The importance of type of breed and stage of maturity. Animal Production, Edinburgh, v.30, n.1, p.135-152, 1980. 